\title{
PUBLIC AND PATIENT INVOLVEMENT IN HEALTH TECHNOLOGY ASSESSMENT: A FRAMEWORK FOR ACTION
}

\author{
Julia Abelson \\ Department of Clinical Epidemiology and Biostatistics, McMaster University \\ abelsoni@mcmaster.ca \\ Frank Wagner \\ University of Toronto \\ Deirdre DeJean, Sarah Boesveld \\ McMaster University \\ Fran sois-Pierre Gauvin \\ McMaster Health Forum \\ Sally Bean \\ Sunnybrook Health Sciences Centre
}

\author{
Renata Axler \\ Odette School of Business, University of Windsor \\ Stephen Petersen \\ Health Quality Ontario \\ Shamara Baidoobonso \\ Cancer Care Ontario \\ Gaylene Pron \\ Health Quality Ontario \\ Mita Giacomini, John Lavis \\ McMaster University
}

Objective: As health technology assessment (HTA) organizations in Canada and around the world seek to involve the public and patients in their activities, frameworks to guide decisions about whom to involve, through which mechanisms, and at what stages of the HTA process have been lacking. The aim of this study was to describe the development and outputs of a comprehensive framework for involving the public and patients in a government agency's HTA process.

Methods: The framework was informed by a synthesis of international practice and published literature, a dialogue with local, national and international stakeholders, and the deliberations of a government agency's public engagement subcommittee in Ontario, Canada.

Results: The practice and literature synthesis failed to identify a single, optimal approach to involving the public and patients in HTA. Choice of methods should be considered in the context of each HTA stage, goals for incorporating societal and/or patient perspectives into the process, and relevant societal and/or patient values at stake. The resulting framework is structured around four actionable elements: (i) guiding principles and goals for public and patient involvement (PPI) in HTA, (ii) the establishment of a common language to support PPI efforts, (iii) a flexible array of PPI approaches, and (iv) on-going evaluation of PPI to inform adjustments over time.

Conclusions: A public and patient involvement framework has been developed for implementation in a government agency's HTA process. Core elements of this framework may apply to other organizations responsible for HTA and health system quality improvement.

Keywords: Public involvement, Patient involvement, Framework, Health technology assessment

For approximately a decade, health technology assessment (HTA) organizations in Canada and around the world have been involving the public and patients in their work, a domain that has typically been dominated by scientific and clinical experts (1-4). Much of this activity falls under the banner of public and patient involvement (PPI), a term used to capture a broad range of efforts to involve members of the public and patients in processes that guide health system decision making. The increased attention being given to PPI in the HTA arena has been observed in several recent surveys and reviews of international practice $(2 ; 5-7)$, most of which have documented progress on this front as incremental and piecemeal.

Ontario has led some of the early PPI developments in the Canadian HTA field (8). In 2007, the Ontario Health Tech- nology Advisory Committee (OHTAC) ${ }^{1}$, now a standing committee of Health Quality Ontario (HQO), which makes recommendations about health interventions to the health system and the Ontario Ministry of Health and Long-Term Care (9), formed a Public Engagement (PE) Subcommittee to guide its early efforts in this area (10). The PE Subcommittee's recommendations led to the introduction of several opportunities for public and patient involvement within its HTA process (Figure 1). Most notably, OHTAC established a 21-day

\footnotetext{
${ }^{1}$ In 2010, OHTAC became a standing committee of Health Quality Ontario (HQO) and reports to the HQO Board. HQO's Evidence Development and Standards Division (EDS) manages the evidence review process that supports the OHTAC deliberations which informs its recommendations.
} 

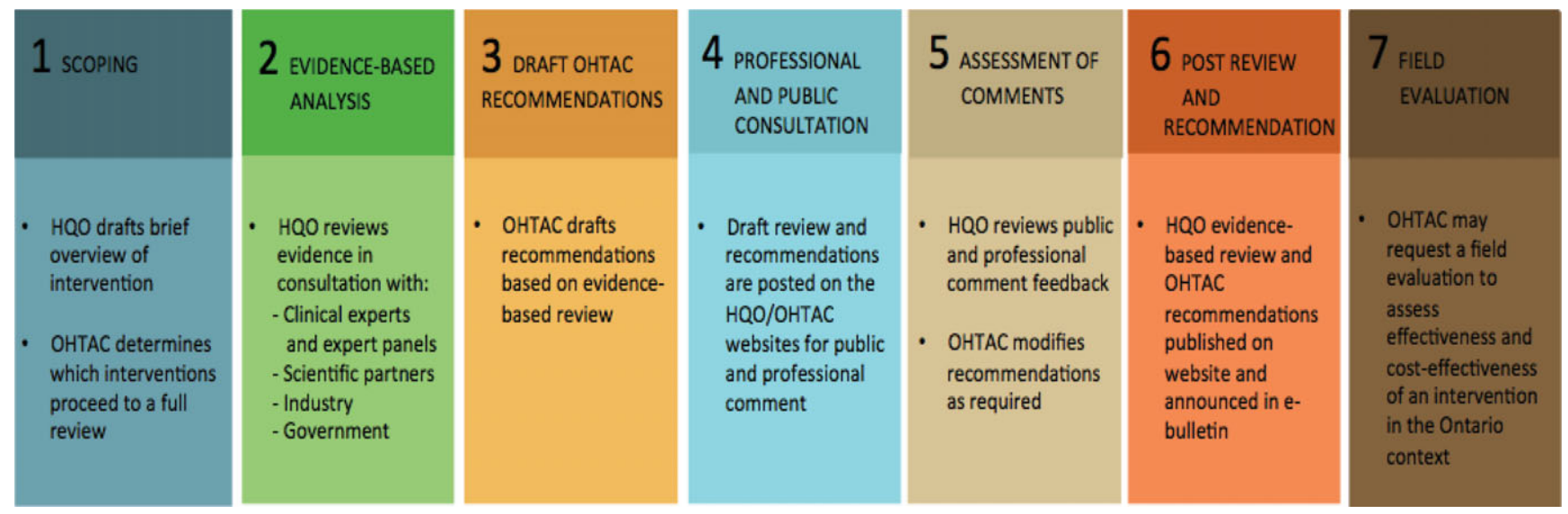

Figure 1. HQO-OHTAC HTA process. HQO, Health Quality Ontario; OHTAC, Ontario Health Technology Advisory Committee. Note: This was the HQO Evidence Review Process at the time of the PE Subcommittee deliberations.

public and professional consultation process for draft OHTAC recommendations. Additionally, enhanced Web-based communication mechanisms were established to post information about the agency's HTA process, draft HTA recommendations and reports, and to elicit wide-ranging input on draft and final recommendations (11).

In addition to these institutionalized PPI mechanisms, between 2008 and 2010, OHTAC experimented with several ad-hoc initiatives for involving the public and patients at various stages in the HTA process (12-14). While each experience yielded outputs that informed specific health technology assessments, addressing the more comprehensive task of sorting out which patients and publics to involve with what methods and at which juncture in the HTA process, has remained an elusive goal in the HTA literature and in practice. This study addresses this gap by reporting on the development and outputs of a comprehensive framework for involving the public and patients in a government agency's HTA process.

\section{METHODS}

The deliberations of OHTAC's PE Subcommittee ("Subcommittee"), together with an independently funded research project led by the first author, informed the framework's development. The Subcommittee met monthly between January 2013 and July 2014. Three evidentiary sources informed its deliberations: a Web site review of HTA organizations, a review of published literature about PPI in HTA, and a stakeholder dialogue $(15 ; 16)$. Sources addressed the following questions: (i) Why are HTA organizations involving the public and patients? (goals and rationales). (ii) How are they doing this? (descriptive evidence about involvement approaches, including who is being involved and through which mechanisms). (iii) With what results? (evaluative evidence about the effectiveness of PPI approaches). (iv) What are the barriers, challenges, and facilitators of PPI in HTA organizations? (feasibility considerations)

\section{Web Site Scan and Literature Review}

We conducted a systematic Web site scan of international HTA agencies in August 2013. We identified eighty-three HTA agencies from forty-six countries from the member lists of EuNeHTA, INAHTA, Euroscan, and organizations reporting to the NIHR HTA Database. Member organizations included a mix of supportive and responsible HTA agencies. We included agencies with English-language Web sites $(n=$ $17)$ or in-house translation capabilities $(n=36)$, which narrowed the sample to 53 HTA agencies across 34 countries. We scanned the Web sites for relevant links, followed by a keyword search using the terms "public participation", "public engagement", "public involvement", "consumer involvement", and "patient involvement". We also gathered relevant documents from the Patient and Citizen Involvement section of the Health Technology Assessment international's (HTAi) Web site. We managed the extracted data and analysis using Excel $^{\circledR}$.

For literature sources, we included published surveys of international HTA practice related to PPI $(2 ; 6 ; 7 ; 17)$, a small but highly relevant set of reviews of empirical studies and conceptual analyses of PPI in HTA published between 2007 and 2011 $(3 ; 5 ; 18)$, and recent empirical and conceptual studies using the search strategy developed by Gagnon et al. (5) for PubMed. The latter retrieved 360 potentially relevant papers published from February 1, 2009, to September 25, 2013. After reviewing titles and abstracts for relevance, we discarded papers that did not address PPI and retained 30 empirical papers and twelve conceptual papers for full-text review. A qualitative content analysis of these recent papers, together with previously published surveys and reviews $(2 ; 3 ; 5-7 ; 17 ; 18)$, captured evidence published from 1990-2013.

\section{Stakeholder Dialogue}

In May 2014, we convened a stakeholder dialogue with nineteen participants: two policymakers, six managers, four researchers, and four citizens from across Canada, and three 
international researchers. Five participants were either members of HQO personnel or the PE Subcommittee. The dialogue examined the problem of PPI in HTA, elements of a comprehensive approach for addressing it, and implementation considerations. We precirculated to participants an evidence brief (15) organized around each of these three dialogue topics. The event produced a dialogue summary (16) that provided new information and critical input to the Subcommittee's deliberations and recommendations. The contents of these documents are publicly available (16).

\section{Framework Development Process}

The framework development process followed an iterative approach comprised of three phases. The first phase involved critical reflection on the descriptive and evaluative results of the Web site scan and literature review. These sources provided the Subcommittee with essential guidance about current international practice, the available evidence to support different approaches, and feasibility and implementation considerations. A second phase established the conceptual foundation for the framework, drawing on material gathered during the first phase with a focus on seeking clarity about key terms such "patients", "the public", "involvement", and "engagement", and the establishment of guiding principles for determining when and how to involve patients and the public in Ontario's HTA process. The final phase involved the integration of the outputs of the first two phases with those of the evidence brief-informed stakeholder dialogue to produce the conceptually robust, evidenceinformed framework for public and patient involvement that follows.

\section{RESULTS}

\section{Web Site Scan and Literature Synthesis Results}

Web site and literature content addressed four key themes: (i) the goals or rationales provided for PPI; (ii) the PPI approaches used at different stages in the HTA process; (iii) evidence of effectiveness or impact of involvement; and (iv) feasibility considerations, including barriers to and facilitators of PPI.

\section{Goals and Rationales for Public and Patient Involvement}

Our review of HTA Web sites identified only a small number $(n=5)$ of organizations that articulated a clear set of goals or rationales for involving the public or patients in their activities (19-23). They highlight 3 main goals for PPI: (i) improving the relevance of assessments (19;21;22); (ii) strengthening the research and complementing the expertise of healthcare professionals and researchers (21-23); or (iii) enhancing procedures, that is, the openness and inclusiveness of the decision process (20).

The published literature offers a more conceptually rich discussion of the goals for PPI. Earlier work, which first ap- plied theories of public participation to HTA, is especially illuminating. From a democratic perspective, PPI may be a means for promoting accountable health systems that respond to public and patients' values and expectations, and taxpayers' financial stakes in publicly financed health systems (24-26). Contexts of scarce resources and rapid technological change present policymakers with complex and contentious funding decisions $(27 ; 28)$. These contribute to the emergence of PPI mechanisms as a political imperative for more informed, transparent, accountable, and legitimate decisions about health technologies $(3 ; 18)$.

The value of PPI has also gained traction as a way of promoting a more comprehensive approach to HTA rather than relying solely on clinical and cost-effectiveness evidence. The political and ethical backdrops of the health technology policy landscape have precipitated a more comprehensive approach to determine which technologies a publicly funded health plan can justify morally, economically, and functionally. In recent years, researchers and HTA agencies have given more serious consideration to incorporating social values and ethics into HTAs $(29 ; 30)$, to greater patientfocused HTAs that incorporate the patients' values, needs, preferences, and lived experiences $(4 ; 29 ; 31)$, and to involving a broader range of stakeholders including patients and service users as well as the broader public in conducting HTAs $(3 ; 4 ; 30)$.

PPI in HTA may also achieve instrumental goals, to make better quality decisions across all the stages of an HTA (3). For example, HTA agencies may seek the most meaningful ways to gather public and patient input to improve the prioritizing of requests, the scoping of the assessment topic, the development of recommendations, or the dissemination of findings $(18 ; 29)$. Lastly, PPI may pursue developmental goals, such as increasing the public's understanding of health technologies and HTA, as well as strengthening the public's and patients' competence and capacity to contribute to health technology-policy issues $(3 ; 18)$.

More recent published discussion echoes and builds on these goals. Generally, making the work of HTA agencies relevant to the public is cited as necessary to gain public support for its funding (6;32). Menon and Stafinski (6) advocate patient involvement in every step of the HTA process, to ensure that the assessment adopts a broader health condition perspective, rather than the narrower technology perspective characteristic of more traditional HTAs. Gagnon et al. $(5 ; 33)$ cite three key rationales for PPI. First, PPI provides context for the research, which improves the usefulness of assessments for decision makers. In turn, this improves the appropriateness and applicability of the recommendations that arise from HTAs. Second, PPI might contribute to better acceptability, adoption, and implementation of recommendations. Finally, PPI focuses on the primary beneficiaries of the decisions. 


\section{Public and Patient Involvement Approaches}

Our Web site scan identified thirteen of the fifty-three HTA agencies (25 percent) with documented approaches to PPI (20;22;23;34-44), roughly consistent with proportions documented by previous surveys $(2 ; 7)$. It is worth noting that decisions to undertake PPI activities within agencies that support other agencies responsible for HTA decision making may be constrained by the scope and funding received for their work; however, we were unable to assess this objectively. The most commonly used PPI approach ( $n=8$ agencies) is to have patients and/or members of the public directly participate on committees of the agency $(19 ; 23 ; 34 ; 37 ; 41 ; 42 ; 44)$; very few responding agencies indicated that they had engaged the public through more participatory approaches $(7 ; 17)$.

Conversely, the results of a self-reported survey of HTA agencies identified a much stronger emphasis on communication and consultation mechanisms (7). The most commonly used mechanisms reported in the survey include communicating through public meetings, or consulting through the use of documents or focus groups (7). Many of the agencies facilitated communication by preparing plain-language versions of their reports to increase accessibility of the assessment (17). Patient organizations also increasingly participate in disseminating HTA findings (17).

Those HTA agencies that use PPI approaches do so across all stages of the HTA process. Most ( $n=7 ; 54$ percent) formally solicit "public comment" toward the end of the HTA process $(11 ; 19 ; 23 ; 41 ; 42 ; 45-47)$. Public reviews of draft documents, surveys, or face-to-face discussions occur most typically at the appraisal and draft recommendation stage (7). At the earliest topic selection stage, six agencies (46 percent) invite the general public to submit assessment requests $(22 ; 34 ; 36 ; 37 ; 41 ; 42)$. The HTA literature notes a trend among HTA agencies toward increased involvement of patients and the public in the early stages of HTA (e.g., topic selection, prioritization, and scoping stages), as well as the value of PPI in the evidence analysis process to capture patient values and experiences $(2 ; 14 ; 48)$. However, only three agencies ( 23 percent) currently claim to involve the public or patients in articulating the research questions to guide the HTA process, or in the evidence collection and analysis process $(23 ; 34 ; 44)$.

\section{Evidence of PPI Effectiveness}

We found minimal evaluation of the effectiveness of PPI or the impacts of involvement on the HTA process or decision making; both Web sites and literature evince this gap $(6 ; 14 ; 49 ; 50)$. The few efforts document potential instrumental benefits (e.g., including patient preferences and patient-relevant outcomes in HTAs) and developmental benefits (e.g., raising public awareness and understanding) (5;51). A small number of ethnographic evaluations document the impacts, and facilitators or barriers, of a particular type of public involvement mechanism, for example, face-to-face citizen deliberations $(14 ; 49 ; 52)$.

\section{PPI Feasibility Considerations}

HTA agency Web sites do not address feasibility considerations related to PPI, but the published literature emphasizes organizational and recruitment challenges $(6 ; 32 ; 53)$. Cultural challenges include tensions between the traditional focus within HTA organizations on clinical and economic evidence, and pressures to incorporate patient and social values input. Public involvement initiatives must combat beliefs that patient views are an anecdotal and biased source of evidence, and perceptions that patients and publics are unable to contribute meaningfully to the process $(6 ; 32 ; 53)$. Some papers also noted perceptions that engaging patients and the public would politicize what should be a solely evidence-informed process (6).

Key organizational challenges include the time, financial resources, and expertise required to support high-quality PPI. Ensuring capacity requires organizational commitment. Recruitment challenges involve struggles to obtain "representative" input, and concerns that PPI will allow narrow interests to trump fairness considerations (48). Enablers to meaningful PPI include a supportive organizational culture, appropriate supports for patient/public committee members and those interacting with them, dedicated time devoted to "patient perspectives" on meeting agendas, and strategic use of new and existing networks of patient organizations for external consultations $(6 ; 29)$.

\section{Framework for Public and Patient Involvement in Ontario's HTA Process}

Informed by the committee deliberations and evidentiary sources discussed above, our PPI framework is organized around four actionable elements detailed in the following sections.

\section{Element 1: Articulate the Principles and Goals for Public and Patient Involvement in HTA}

The committee agreed to six principles that should guide HQO's approach to public and patient involvement: (i) purposeful; (ii) pragmatic; (iii) fair and equitable; (iv) proportional; (v) evidence-informed; and (vi) transparent (Supplementary Table 1). Many of these principles are common to the values identified in HTAi's Values and Quality Standards for Patient Involvement in HTA, which resulted from an 18-month Delphi consensus process with input from 150 respondents in thirtynine countries worldwide (54).

Linked to these principles is a set of operational goals specific to the HQO-OHTAC process, and which provide the foundation for the PPI framework:

1. PPI will be strengthened and supported: (i) to improve the quality of the outputs that arise from each stage of the HQO-OHTAC process; (ii) to create more informed, transparent, accountable and legitimate processes for deliberating about health technologies; (iii) to promote a more 
Abelson et al.

Table 1. Building a common language for public and patient involvement in HTA

Goals for public and patient involvement
• improving the quality of HQO-OHTAC recommendations
- improved transparency and accountability of the HQO-OHTAC process
- increased knowledge and awareness of HQO-OHTAC recommendations

Which groups?
The public (citizens, interested members of the general public without direct experience with a
specific technology or condition)
Patients, families and caregivers (with experience with a specific technology or condition)
Stakeholder group (groups with an organized interest in a technology or condition)

HQO, Health Quality Ontario; OHTAC, Ontario Health Technology Advisory Committee. robust and comprehensive science of HTA that investigates social values and ethics, as well as patients' problems, lived experiences, outcomes, and preferences; (iv) to increase public and patient understanding of health technologies and HTA, and to strengthen the public's and patients' competence and capacity to contribute to various stages of the health technology assessment process.

2. PPI efforts will be informed by evidence (where possible), best practice in the absence of evidence, and sound principles.

3. Evaluation is to be embedded into all aspects of HQO's PPI activities given the lack of a strong evidence base in this area and given HQO-OHTAC's emphasis in this area.

4. PPI efforts will support and, in turn, be supported by HQO's decisionmaking framework, which includes a specific emphasis on the incorporation of social values and ethics into the evidence-review process.

\section{Element 2: Establish a Common Language to Support Public and Patient Involvement Efforts}

Conceptual and empirical studies have noted divergent views within the HTA community, about what "public and patient involvement" means (18). This ambiguity can lead to conflicting goals and visions for PPI in HTA $(2 ; 7 ; 17 ; 18)$, and more practically, conflicting views about who should be engaged, who they represent, what role they should play at different stages of the HTA process, and using what types of involvement mechanisms $(6 ; 7 ; 18)$. Our framework emphasizes the importance of establishing a common language to effectively support efforts to involve the public and patients in the HTA process. Informed by the literature synthesis, we defined the "who" of PPI with three categories of relevant perspectives: (i) public (or publics or citizens); (ii) patients, family members, and caregivers; and (iii) stakeholders (Supplementary Figure 1).

The "what" of PPI was established by adopting Rowe and Frewer's (55) typology of involvement, which includes three commonly cited levels of involvement: communication, consul- tation, and participation (Supplementary Figure 2). Each type reflects a different set of relationships between the initiator of the involvement activity and the participants. Taken together, these mechanisms are often portrayed as a spectrum of involvement with increasing opportunities for participants to be empowered through each stage of the PPI process. These conceptualizations are linked to illustrate the early but critical step in any PPI strategy where key decisions are made about which publics to involve and how, guided by explicit goals (Table 1).

\section{Element 3: Describe a Flexible Menu of Public and Patient Involvement Approaches}

A key message from the Web site scan and literature synthesis is that there is no one-size-fits-all approach to PPI. Rather, the choice of method should be considered in the context of each HTA stage and matched to the motivation for incorporating societal and/or patient perspectives into the process, and the relevant societal and/or patient values at stake. We have undertaken this mapping process in two stages. In the first stage (Figure 2), we have listed the potential goals for PPI that might be pursued in each HTA stage. In the second stage (Figure 3), we have provided a menu of PPI mechanisms and tools that could be used in each of these stages depending on the goal and the societal or patient perspectives sought.

The mapping process focuses on enhancing the transparency, legitimacy, and overall quality of at the front end of the HQO-OHTAC process, especially in the topic selection and scoping stages. This emphasis reflects the Subcommittee's priorities to facilitate increased awareness and understanding among interested patients, broader publics, and stakeholder groups, and about how topics are selected for review and appraisal, a stage of the HTA process that is opaque in most HTA organizations. 

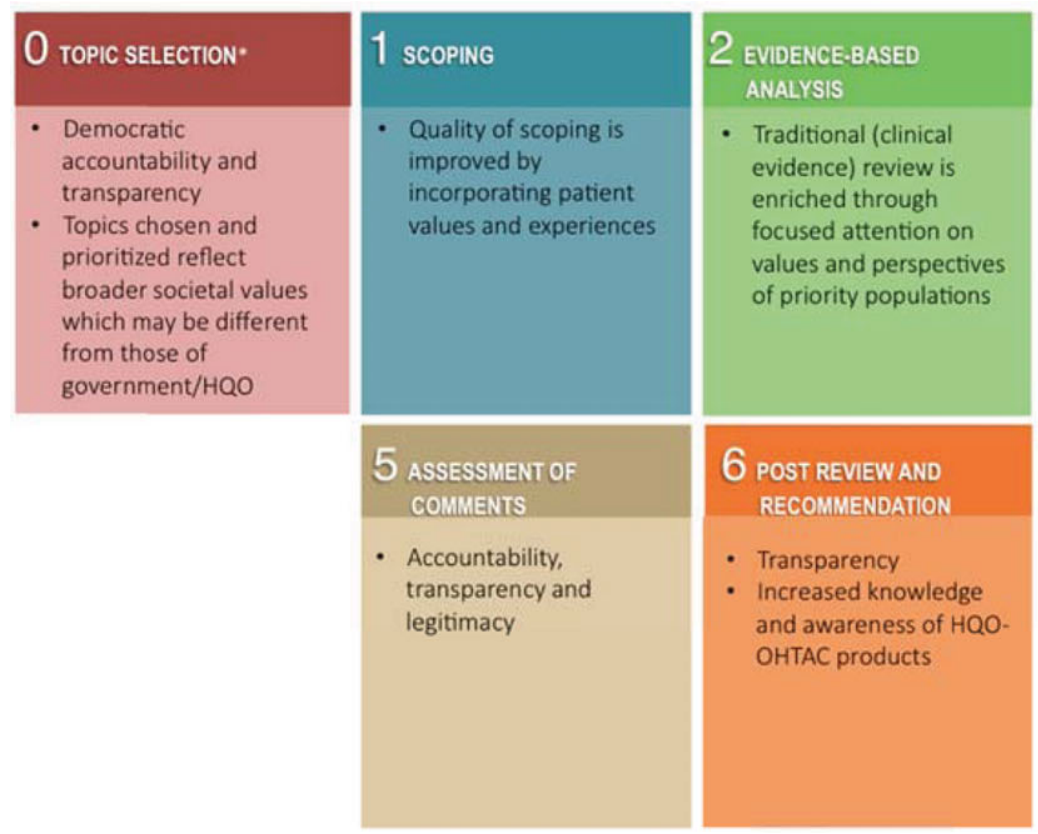
and awareness of HQO-
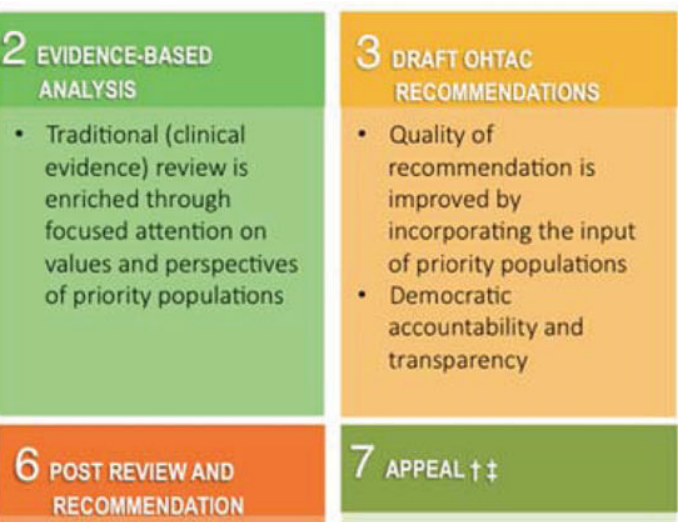

7 APPEAL $\$$

- Transparency

- Increased knowledge OHTAC products
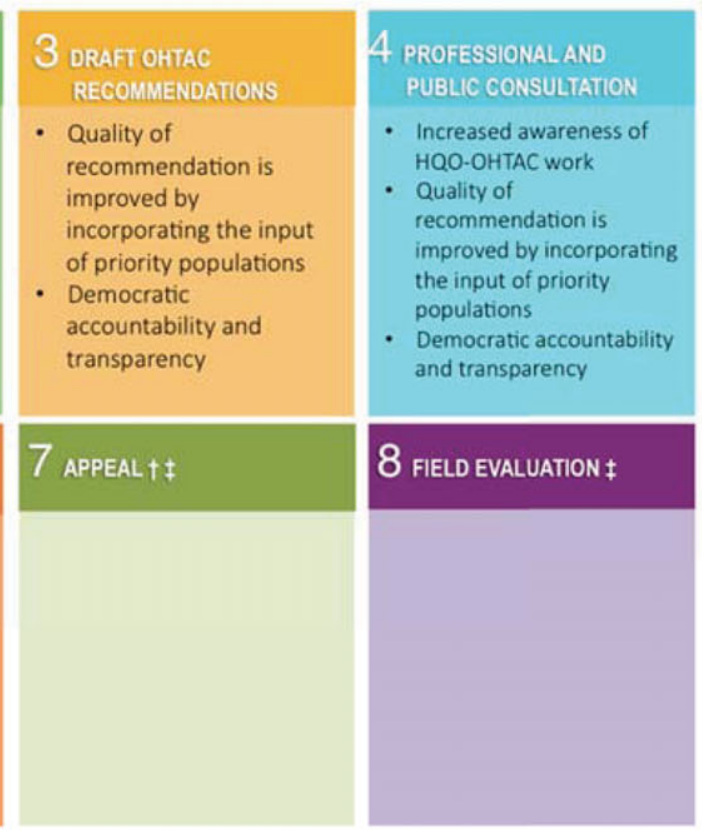

Figure 2. Rationales and Goals for Patient and Public Involvement by HTA Stage. *Newly proposed stage to provide early opportunity for PPI. †This stage was added following the tabling of the subcommittee's report in July 2014. ¥Not addressed by the subcommittee. HQO, Health Quality Ontario; HTA, Health Technology Assessment; OHTAC, Ontario Health Technology Advisory Committee.
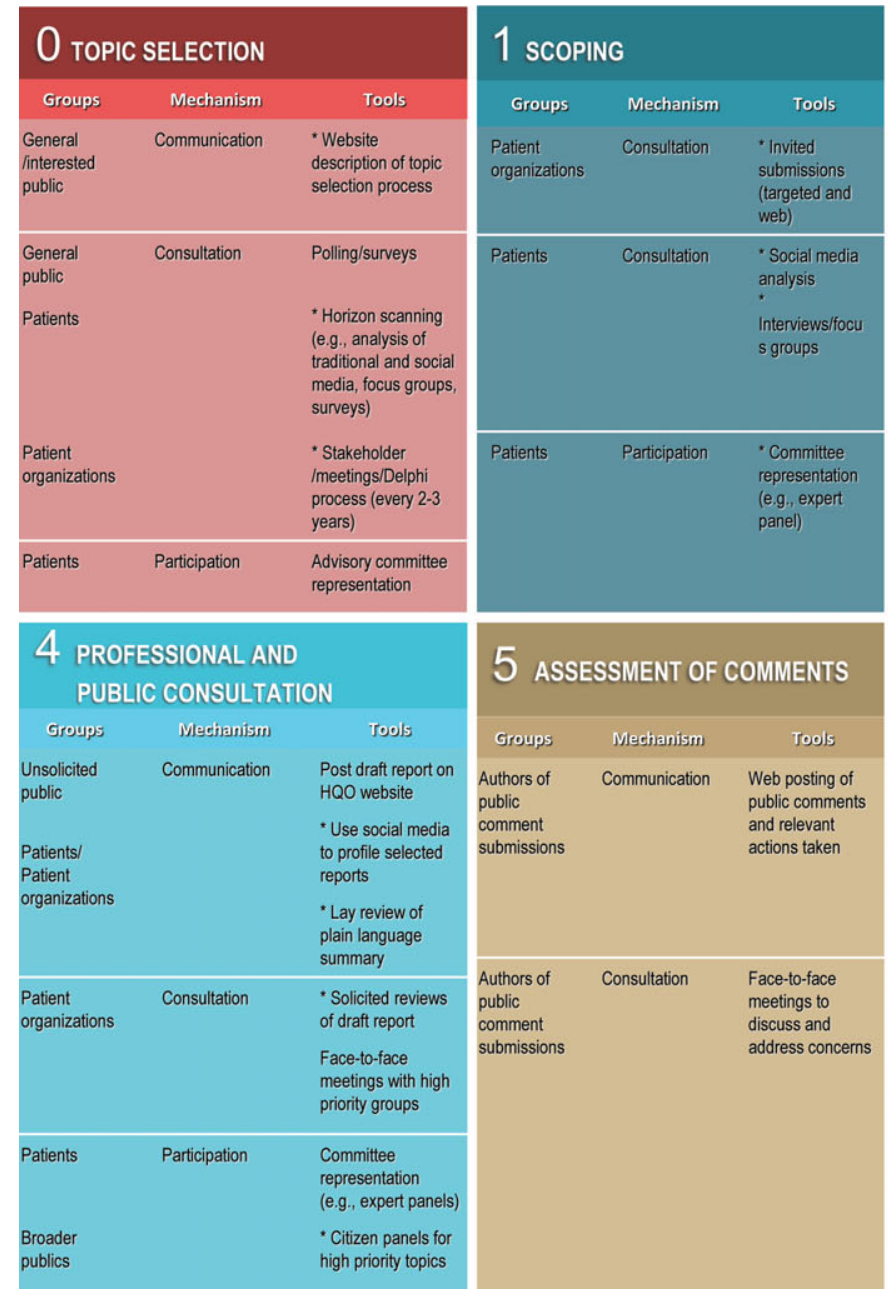
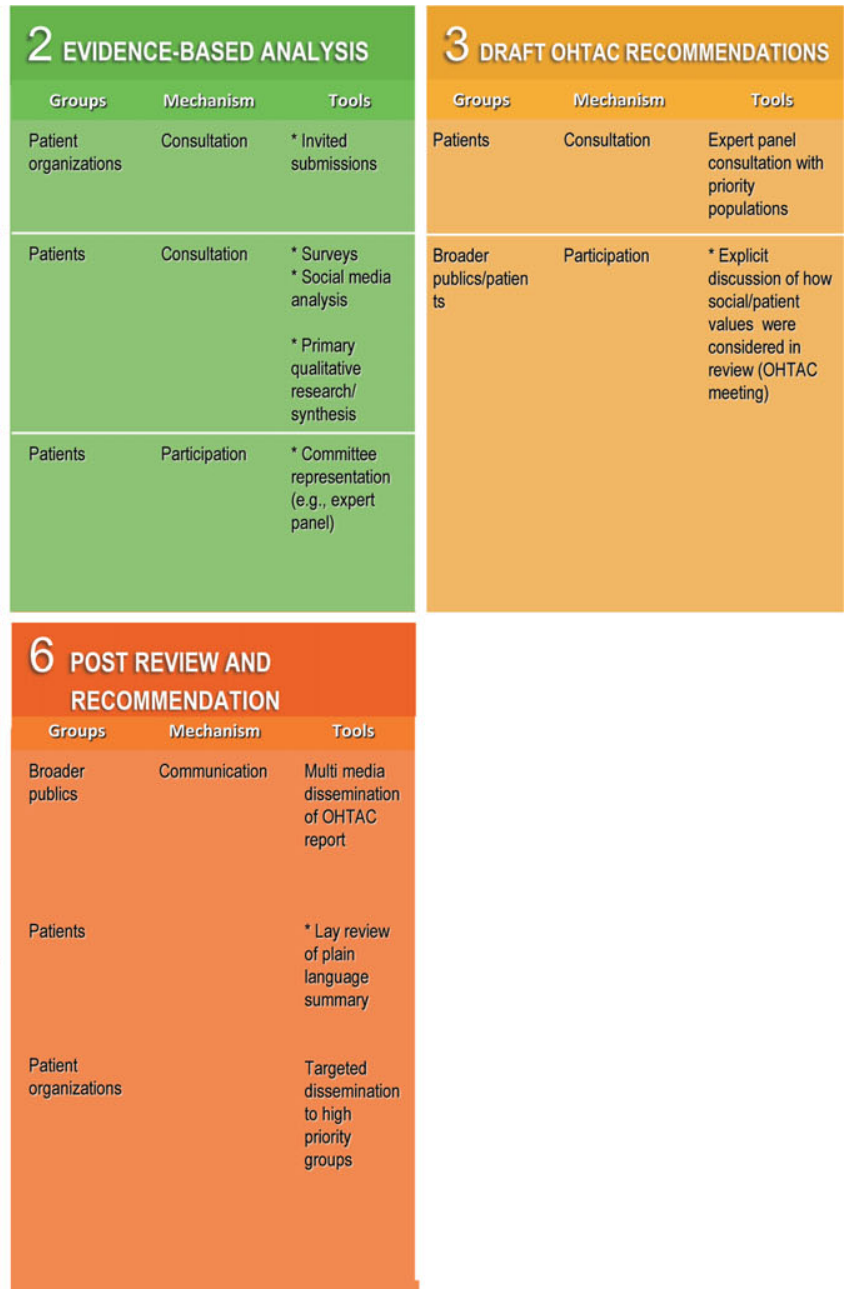

Figure 3. Who to Involve and How by HTA Stage. *Indicates link to Subcommittee report recommendation. HQO, Health Quality Ontario; HTA, Health Technology Assessment; OHTAC, Ontario Health Technology Advisory Committee. 
Seen as equally important was the need to increase the relevance and responsiveness of OHTAC's work by undertaking consultation and participation activities to prospectively identify potential review topics and emerging issues of concern to patients and priority populations, and to ensure that the framing of the questions guiding the evidence review process reflect the values of relevant health technology users. These areas of emphasis were reinforced by our synthesis of the evidence, which revealed increased attention to, and sophistication of, the methods used to involve patients and citizens in these early HTA stages (e.g., patient members of expert panels, on-line and face-to-face consultations with individual patients, and/or patient groups, and the synthesis of primary qualitative research studies about patients' views and experiences).

The committee also sought to strengthen and diversify the communication and consultation activities already present in the later stages of the HQO-OHTAC process, again, to enhance the awareness of OHTAC's work among relevant populations, and to encourage broader input on its draft recommendations.

\section{Element 4. Measurement and Evaluation}

Given the weak evidence base for PPI in the HTA field, efforts in this regard should initially focus on basic formative evaluation metrics to determine whether the intended goals of the PPI activities are being achieved, including basic process and impact measures such as numbers and types of consultations, how different types of PPI input are being used in the various stages of the HTA process, and the resources required to carry out relevant activities. These will provide valuable information to inform mid-course adjustments to approaches. Over time, more robust evaluation metrics could be developed, allowing the possibility to compare different PPI approaches using trial and quasi-experimental designs consistent with several recently published high-quality public involvement evaluation studies in related fields $(56 ; 57)$.

\section{DISCUSSION}

Our framework makes novel and important contributions to the field of public and patient involvement in HTA. First, it explicitly identifies a range of goals that might guide HTA activities and links these to different constituencies of patients and citizens, and appropriate PPI mechanisms. Explicit mapping of PPI goals to participants, and approaches, has been absent from international HTA, and other health system, PPI practices. Second, we systematically map these PPI goals, participants, and approaches through each stage of a government agency's HTA process. Together these provide organizations with a comprehensive menu of options, indicating specific goals and stages that may warrant PPI and which approaches may add value beyond current efforts. Third, our framework closely aligns with the mission of the responsible government agency and its current efforts to refresh its decision-making framework, which features four attributes: (i) overall clinical benefit, (ii) value for money, (iii) social values and ethics, and (iv) feasibility. The framework suggests specific ways PPI may inform these decision criteria, bringing rigor and sophistication particularly to the task of integrating social and patient value judgments with clinical and economic evidence into the HTA process.

As a product of a committee process embedded within a large government agency, the framework development process faced several constraints. Emphasis on pragmatism and implementation feasibility may have come at the expense of comprehensiveness. The Subcommittee's timeline of 18 months prevented the piloting of key framework elements, which may have improved its robustness. The compressed timeframe also limited the committee's ability to comprehensively address the central question of which health technologies might be good candidates for a PPI strategy and what criteria should guide these decisions. Finally, the tailoring of the framework to the specific HTA context of a government agency in Ontario, Canada may limit its relevance to organizations with broader or more limited HTA mandates.

These limitations may also be viewed as strengths. In particular, the pragmatic approach taken by a committee membership with diverse backgrounds and experiences related to HTA, and other health system settings, likely contributed to a more grounded product that resonates with organizations facing similar challenges. Moreover, the alignment of the committee's work with an independently funded research team focused on a similar set of objectives, with access to multiple data sources, including the reflections from a stakeholder dialogue, were unique features that likely strengthened the quality of the final product and its applicability to a variety of settings.

\section{Uptake of the Framework and Corresponding Recommendations}

The PPI framework was accompanied by a series of recommendations designed to make measurable progress over a short period of time and with limited resource investments (11). The Board of HQO received these recommendations in October 2014 and has subsequently moved toward implementing several of them (58).

\section{CONCLUSION}

The framework presented combines a strong conceptual foundation with actionable elements informed by a synthesis of international practice and published research evidence, and a dialogue with Canadian and international stakeholders. As such, the framework as a whole, or selected core elements, should be broadly applicable to other HTA agency processes in Canada, and to other health system organizations pursuing similar health quality agendas. We encourage these organizations to consider this framework as they work toward strengthening their PPI practices. 


\section{SUPPLEMENTARY MATERIAL}

Supplementary Table 1:

http://dx.doi.org/10.1017/S0266462316000362

Supplementary Figure 1:

http://dx.doi.org/10.1017/S0266462316000362

Supplementary Figure 2:

http://dx.doi.org/10.1017/S0266462316000362

\section{CONFLICTS OF INTEREST}

The authors report no conflicts of interest.

\section{REFERENCES}

1. Hailey D. Consumer involvement in health technology assessment. Edmonton, Canada: Alberta Heritage Foundation for Medical Research; 2005.

2. Hailey D, Werko S, Bakri R, et al. Involvement of consumers in health technology assessment activities by Inahta agencies. Int $J$ Technol Assess Health Care. 2013;29:79-83.

3. Abelson J, Giacomini M, Lehoux P, Gauvin FP. Bringing 'the public' into health technology assessment and coverage policy decisions: From principles to practice. Health Policy. 2007;82:37-50.

4. Bridges JF, Jones C. Patient-based health technology assessment: A vision of the future. Int J Technol Assess Health Care. 2007;23:30-35.

5. Gagnon MP, Desmartis M, Lepage-Savary D, et al. Introducing patients' and the public's perspectives to health technology assessment: A systematic review of international experiences. Int J Technol Assess Health Care. 2011;27:31-42.

6. Menon D, Stafinski T. Role of patient and public participation in health technology assessment and coverage decisions. Expert Rev Pharmacoecon Outcomes Res. 2011;11:75-89.

7. Whitty JA. An international survey of the public engagement practices of health technology assessment organizations. Value Health. 2013;16:155163.

8. Levin L, Goeree R, Sikich N, et al. Establishing a comprehensive continuum from an evidentiary base to policy development for health technologies: The Ontario experience. Int J Technol Assess Health Care. 2007;23:299-309.

9. Health Quality Ontario. Excellence Through Evidence 2016 [cited August 10, 2016]. http:/www.hqontario.ca/Evidence-to-Improve-Care/ Excellence-Through-Evidence

10. Public Engagement Subcommittee of the Ontario Health Technology Advisory Committee. Final Report. Toronto, ON: Ontario Health Technology Advisory Committee; 2007.

11. OHTAC Public Engagement Subcommittee. Public engagement for health technology assessment at Health Quality Ontario-Final report from the Ontario Health Technology Advisory Commit- 649 tee Public Engagement Subcommittee [Internet]. Toronto: 2015. http://www.hqontario.ca/Portals/0/documents/evidence/special-reports/ report-subcommittee-20150407-en.pdf.

12. Bombard Y. Public engagement pilot study on point-of-care International Normalized Ratio (INR) monitoring devices. Toronto, Canada: Medical Advisory Secretariat, Ontario Ministry of Health and Long Term Care; 2009.

13. Bombard Y, Abelson J, Simeonov D, Gauvin FP. Eliciting ethical and social values in health technology assessment: A participatory approach. Soc Sci Med. 2011;73:135-144.

14. Abelson J, Bombard Y, Gauvin FP, Simeonov D, Boesveld S. Assessing the impacts of citizen deliberations on the health technology process. Int J Technol Assess Health Care. 2013;29:282-289.
15. Gauvin FP, Abelson J, Lavis J. Evidence brief: Strengthening public and patient engagement in health technology assessment in Ontario. Hamilton, Canada: McMaster Health Forum; May 8, 2014.

16. Gauvin FP, Lavis J. Dialogue summary: Strengthening public and patient engagement in health technology assessment in Ontario. Hamilton, Canada: McMaster Health Forum; May 8, 2014.

17. Hailey D, Nordwall M. Survey on the involvement of consumers in health technology assessment programs. Int J Technol Assess Health Care. 2006;22:497-499.

18. Gauvin FP, Abelson J, Giacomini M, Eyles J, Lavis JN. "It all depends": Conceptualizing public involvement in the context of health technology assessment agencies. Soc Sci Med. 2010;70:1518-1526.

19. National Institute for Health Care Excellence. Patient and Public Involvement Programme 2014 [updated 20140/04/10/]. http://www.nice.org.uk/getinvolved/patientandpublicinvolvement/ ppipinvolvementprogramme.jsp.

20. Washington Health Technology Assessment Program (Washington State). Health Technology Assessment Program 2014 [cited June 23, 2014]. http://www.hca.wa.gov/hta/Pages/index.aspx.

21. National Institute for Health Research. NIHR Evaluation Trials and Studies Coordinating Centre [cited June 23, 2014]. http://www.netscc. ac.uk.

22. Center for New Health Technology Assessment. Center for New Health Technology Assessment [cited June 23, 2014]. http://neca.re.kr/nHTA/ eng/.

23. pan-Canadian Oncology Drug Review. pan-Canadian Oncology Drug Review [cited June 23, 2014]. http://www.pcodr.ca/.

24. Wynne B. Public engagement as a means of restoring public trust in science - Hitting the notes, but missing the music? Community Genet. 2006;9:211-220.

25. Abelson J, Eyles J. Public participation and citizen governance in the Canadian health system. In: Forest PG, McIntosh T, Marchildon G, eds. Changing health care in Canada: The Romanow Papers, Volume 2. Toronto, Canada: University of Toronto Press; 2004.

26. Bovens M. Public Accountability. In: Ferlie E, Lynn LE, Pollitt C, eds. Oxford handbook of public management. Oxford, United Kingdom: Oxford University Press; 2007.

27. Chinitz D. Health technology assessment in four countries: Response from political science. Int J Technol Assess Health Care. 2004;20:55-60.

28. Coulter A, Ellins J. Effectiveness of strategies for informing, educating, and involving patients. BMJ. 2007;335:24-27.

29. Facey K, Boivin A, Gracia J, et al. Patients' perspectives in health technology assessment: A route to robust evidence and fair deliberation. Int J Technol Assess Health Care. 2010;26:334-340.

30. DeJean D, Giacomini M, Schwartz L, Miller FA. Ethics in Canadian health technology assessment: A descriptive review. Int J Technol Assess Health Care. 2009;25:463-469.

31. Lehoux P. The problem of health technology: Policy implications for modern health care systems. New York, NY: Routledge: Taylor \& Francis Group; 2006.

32. Drummond M, Tarricone R, Torbica A. Assessing the added value of health technologies: Reconciling different perspectives. Value Health. 2013;16(Suppl):S7-S13.

33. Gagnon MP, Desmartis M, Gagnon J, et al. Introducing the patient's perspective in hospital health technology assessment (HTA): The views of HTA producers, hospital managers and patients. Health Expect. 2014;17:888-900.

34. National Institute for Health Research. Health Technology Assessment (HTA) Programme [cited June 23, 2014]. http://www.nets.nihr.ac.uk/ programmes/hta.

35. Adelaide Health Technology Assessment Centre. About Adelaide Health Technology Assessment (AHTA) 2014 [cited June 23, 2014]. http:// www.adelaide.edu.au/ahta/. 
36. Swedish Council on Technology Assessment in Health Care. SBU Swedish Council on Health Technology Assessment [cited June 23, 2014]. http://www.sbu.se/en/.

37. KCE - Belgian Health Care Knowledge Centre. KCE - Belgian Health Care Knowledge Centre, [cited June 23, 2014]. http://kce.fgov.be.

38. Australian Safety and Efficacy Register of New Interventional Procedures - Surgical (ASERNIP-S). Mission Statement [cited June 23, 2014]. http://www.surgeons.org/for-health-professionals/auditsand-surgical-research/asernip-s.

39. Health Evidence Review Commission (Oregon). Health Technology Assessment Subcommittee Meeting Archives [cited June 23, 2014]. http:// www.oregon.gov/oha/herc/Pages/htasArchive.aspx.

40. National Institute for Health Research. Horizon Scanning Centre [cited June 23, 2014]. http://www.hsc.nihr.ac.uk.

41. Medical Services Advisory Committee. Medical Services Advisory Committee [cited June 23, 2014]. http://www.msac.gov.au/.

42. Healthcare Improvement Scotland. Healthcare Improvement Scotland [cited August 10, 2016]. http://healthcareimprovementscotland.org/.

43. New Zealand National Health Committee. New Zealand National Health Committee [cited June 23, 20143]. http://nhc.health.govt.nz/home.

44. Canadian Agency for Drugs and Technologies in Health. CADTH 2014 [cited June 23, 2014]. http://www.cadth.ca/en/products/cdr/ patient-group-input/.

45. Agency for Healthcare Research and Quality. 2015 [updated July 21, 2015]. http://www.ahrq.gov/.

46. The Health Council of the Netherlands. 2015 [updated July 21, 2015]. http://gezondheidsraad.nl/en.

47. Medical Services Advisory Committee. Call for Public Comment 2014 [updated 20140/04/22/]. http://www.msac.gov.au/internet/msac/ publishing.nsf/Content/surveys-lp.

48. Oliver S, Armes DG, Gyte G. Public involvement in setting a national research agenda: A mixed methods evaluation. Patient. 2009;2:179190.
49. Jones M, Einsiedel E. Institutional policy learning and public consultation: The Canadian xenotransplantation experience. Soc Sci Med. 2011;73:655-662.

50. Chambers D, Wilson PM, Thompson CA, et al. Maximizing the impact of systematic reviews in health care decision making: A systematic scoping review of knowledge-translation resources. Milbank Q. 2011;89: 131-156.

51. Moran R, Davidson P. An uneven spread: A review of public involvement in the National Institute of Health Research's Health Technology Assessment program. Int J Technol Assess Health Care. 2011;27:343347.

52. Davies C, Wetherell M, Barnett E. Citizens at the centre: Deliberative participation in health care decisions. Bristol, UK: The Policy Press; 2006.

53. Gauvin FP, Abelson J, Giacomini M, Eyles J, Lavis JN. Moving cautiously: Public involvement and the health technology assessment community. Int J Technol Assess Health Care. 2011;27:43-49.

54. Health Technology Assessment International. Patient and Citizen Involvement 2014 [updated 20140/04/10/]. http://www.htai.org/index. php?id=545.

55. Rowe G, Frewer LJ. A typology of public engagement mechanisms. Sci Technol Human Values. 2005;30:251-290.

56. Carman KL, Heeringa JW, Heil SKR, et al. Public deliberation to elicit input on health topics: Findings from a literature review. Rockville, MD: Agency for Healthcare Research and Quality; 2013.

57. Boivin A, Lehoux P, Lacombe R, Burgers J, Grol R. Involving patients in setting priorities for healthcare improvement: A cluster randomized trial. Implement Sci. 2014;9:24.

58. Health Quality Ontario. Excellence through evidence: Roadmap for evidence-based recommendations and quality standards. [Internet]. Toronto: 2015. http://www.hqontario.ca/Portals/0/ Documents/evidence/reports/excellence-through-evidence-1511en.pdf. 